\title{
Optimization of Fermentation Parameters for Beer Production from Buckwheat (Fagopyrum esculentum) Grains
}

\author{
Praja K. Malaganve* and Geeta G. Shirnalli \\ University of Agricultural Sciences, Dharwad, India \\ *Corresponding author
}

\begin{tabular}{l} 
Ke y w o r d s \\
$\begin{array}{l}\text { Buckwheat beer, } \\
\text { Fermentation, } \\
\text { Gluten free }\end{array}$ \\
\hline Article Info \\
\hline $\begin{array}{l}\text { Accepted: } \\
\text { 20 May 2020 } \\
\text { Available Online: } \\
\text { 10 June } 2020\end{array}$ \\
\hline
\end{tabular}

Buckwheat is a rich source of starch content and can be diverted for beer production using efficient yeast strains and adopting few fermentation parameters. Three standard yeast strains were screened for their efficiency for beer production. The effect of inoculum level of yeast and fermentation period on $\mathrm{pH}$, tannin content, alcohol content and residual reducing sugars were determined. Different yeast inoculum level $(1 \%, 1.5 \%$ and $2 \%)$ were used for fermentation of wort and it was found that the alcohol content was maximum at 2 per cent inoculum level $(5.80 \%)$ while the $\mathrm{pH}$, tannin content and residual reducing sugars were lowest at this concentration. Among the different fermentation period $(5 \mathrm{~d}, 7 \mathrm{~d}$ and $10 \mathrm{~d})$, high alcohol content $(6.15 \%)$ was recorded on the tenth day of fermentation. While the $\mathrm{pH}$, tannin content and residual reducing sugars were least at the tenth day. From the experiment, it was found that the yeast strain Saccharomyces cerevisiae NCIM 3073 pitched into wort at a concentration of 2 per cent followed by a ten days fermentation period gave best results in beer production.

\section{Introduction}

Buckwheat (Fagopyrum esculentum) is a psudocereal that belongs to family Poligonaceae and genus Fagopyrum. Primary gene of buckwheat is originated from wider area of Central Asia. The name buckwheat is derived from two words fagus and pyros. The area of cultivation in the world is doubled in a last decade, from one million to over two million hectares. This cultivated species of plant is notable due to its exceptional nutritive qualities such as rutin, which is an antioxidant (Popovic et al., 2014).

During the period 2010-2011, nearly 2.113 million hectare of buckwheat crop was cultivated worldwide annually. Average yield of the crop during that period was 913 kilogram per hectare. Areas under cultivation and average yield of the crop have shown a rising tendency (Popovic et al., 2014). Being 
a gluten free pseudo cereal, it can be used as an alternate source to beer production. Dezelak et al., (2014) produced beer from buckwheat grains and reported that buckwheat beer was comparable with barley beer and was better when compared with beer prepared from quinoa. Besides, buckwheat also requires minimum fertilizer inputs than barley. Hence, buckwheat could be a new potential substitute for barley and could raise economic benefits. Thus, the present investigation lies in optimising different parameters of fermentation for the production of buckwheat beer.

\section{Materials and Methods}

Standard yeast cultures of Saccharomyces cerevisiae NCIM 3430, NCIM 3391 and NCIM 3073 were obtained from NCIM, Pune and maintained on yeast extract peptone dextrose agar (YEPDA). Overnight grown fresh yeast cultures grown in YEPD broth were used as inoculum. The grains of buckwheat varieties 'PRB-1' and 'Nilgiri local' were selected as source of brewing materials. The grains were malted for 3 days after a soaking period of 16 hours in cold tap water. The malt was then kilned at $50^{\circ} \mathrm{C}$ in a cabinet drier for 24 hours. The kilned grains were broken into grits by running through a mixer at low speed. Mashing programme was then carried out with a grist to water ratio of 1:4 for temperature rests of $65^{\circ} \mathrm{C}$ along with commercial $\alpha$-amylase for maximum saccharification. The concentration of 1 per cent of amylase enzymes (Himedia) at $65^{\circ} \mathrm{C}$ for $16 \mathrm{~h}$ of incubation was used. After mashing, the mash was double filtered through muslin cloth and the hydrolysate (wort) obtained was boiled for an hour. After 30 minutes of boiling hops (acid extracted, Northern Brewer hops) were added @ 40 ppm and sugar was added as an adjunct to make up the brix to $20^{\circ}$ with the help of ERMA refractometer. The wort was cooled, filtered and $\mathrm{pH}$ was adjusted to 5. The wort was the pitched with overnight grown cultures of three yeast strains and kept for aerobic fermentation for $24 \mathrm{~h}$ followed by creating aerobic conditions. The yeast inoculum level used for standardization was 1 per cent, 1.5 per cent and 2 per cent and the fermentation period were 5 days, 7 days and 10 days. The $\mathrm{pH}$, tannin content, alcohol content and residual reducing sugars of the beer samples obtained after fermentation were estimated. The reducing sugars were estimated by 3, 5dinitrosalicylic acid method (Miller, 1959). The $\mathrm{pH}$ of the wort and the beer samples were recorded by using digital $\mathrm{pH}$ meter. Tannins were estimated by Folin-Denis method (Schanderl, 1970) and ethanol was estimated by colorimetric method as described by Caputi et al., (1968).

The experimental results were statistically analysed as per the methods outlined by Panse and Sukhatme (1961) by adopting 'Fisher's analysis of variance technique'.

\section{Results and Discussion}

\section{Effect of yeast strain on alcohol content}

Among three yeast strains Saccharomyces cerevisiae NCIM 3073 produced highest alcohol content (5.22\%), which was found significantly higher than Saccharomyces cerevisiae NCIM 3391 (3.60\%) in case of beer produced from PRB-1 variety. Least alcohol content $(3.37 \%)$ was recorded with the yeast strain Saccharomyces cerevisiae NCIM 3430 (Table 1). But the effect of yeast strains was different when the variety Niligiri local was used as substrate. Here the yeast strain Saccharomyces cerevisiae NCIM 3391 recorded highest alcohol $(3.73 \%)$ which was significantly higher than the strain Saccharomyces cerevisiae NCIM 3073 which produced $3.14 \%$ of alcohol (Table 2). 


\section{Effect of inoculum level on alcohol content}

In both the varieties, as inoculum level increased, alcohol content was also increased significantly (Table 1 and Table 2). The Highest alcohol content (4.65\%) was recorded with 2 per cent inoculum level in the beer produced from PRB-1, which was significantly higher than $1.5 \%$ inoculum level $(3.96 \%)$ and $1 \%$ inoculum level $(4.71 \%)$ in the beer prepared from the same variety. Least alcohol content $(1.57 \%)$ was recorded with 1 per cent inoculum level in the beer prepared from Niligiri local variety of buckwheat.

\section{Effect of yeast strains and inoculum levels on the residual reducing sugars content of the buckwheat beer}

The residual reducing sugars content was inversely related to inoculum levels. Highest residual reducing sugars $(18.79 \mathrm{mg} / \mathrm{g})$ were recorded with the inoculum level of 1 per cent (Table 2) and lowest residual reducing sugars $(11.23 \mathrm{mg} / \mathrm{g})$ were recorded with the inoculum level of 2 per cent (Table 1). The interaction effect between the yeast strains and inoculum levels was significant.

\section{Standardization of period of fermentation}

When compared with Niligiri local, the variety PRB-1 was found to be the better substrate for beer production and when compared with other strains, Saccharomyces cerevisiae NCIM 3073 strain showed better results in both the cases of alcohol production and residual reducing sugars when pitched with two per cent inoculum level. These parameters were selected for the beer production from buckwheat and subjected to the different periods of fermentation for 5,7 and 10 days. The results are presented in Table 3 and Table 4.

\section{Alcohol content}

As the period of fermentation increased, the alcohol content was also increased significantly up to the tenth day of fermentation. Different fermentation days showed significant difference from each other in terms of alcohol content. The highest alcohol content $(6.47 \%)$ was recorded with the fermentation period of ten days, which was significantly greater than 7 days of fermentation $(6.13 \%)$ and the least alcohol content $(5.84 \%)$ was seen in the beer fermented for five days (Table 3 ).

Similar work was done by Nic Phiarais et al., (2010) on processing of a top fermented beer prepared from $100 \%$ buckwheat malt. The malt was pithed with dried yeast (Saccharomyces cerevisiae) and kept for fermentation for four days and authors reported that the yeast produced $4.50 \%$ alcohol content after fermentation.

Dezelak et al., (2014) on the processing of bottom fermented beer from buckwheat malt. The wort was pitched with the liquid yeast culture of Saccharomyces carlsbergensis and kept for fermentation till attenuation was achieved. The final alcohol content was found to be $3.79 \%$ in the beverage obtained.

\section{Residual reducing sugars}

Different periods of fermentation found to have a significant influence on the content of residual reducing sugars. Residual reducing sugars decreased significantly from the fifth day to tenth day of fermentation. The highest residual reducing sugars $(11.22 \mathrm{mg} / \mathrm{g})$ were recorded on the fifth day of fermentation, which was significantly higher than the seventh day of fermentation $(9.767 \mathrm{mg} / \mathrm{g})$. The least reducing sugars $(9.16 \mathrm{mg} / \mathrm{g})$ were obtained on the tenth day of fermentation (Table 3). 
Table.1 Effect of different yeast strains and inoculum levels on alcohol content and residual reducing sugars content in beer produced from buckwheat variety PRB-1

\begin{tabular}{|c|c|c|c|c|c|c|c|c|c|}
\hline \multirow[t]{3}{*}{ Sl. No. } & \multirow[t]{3}{*}{ Strains (A) } & \multicolumn{4}{|c|}{ Alcohol content $(\%)$} & \multicolumn{4}{|c|}{ Residual reducing sugar (mg/g) } \\
\hline & & \multicolumn{8}{|c|}{ Inoculum level (B) } \\
\hline & & $1.0 \%$ & $1.5 \%$ & $2.0 \%$ & Mean & $1.0 \%$ & $1.5 \%$ & $2.0 \%$ & Mean \\
\hline 1 & Saccharomyces cerevisiae NCIM 3430 & 2.82 & 3.18 & 4.13 & 3.38 & 23.66 & 21.54 & 17.09 & 20.76 \\
\hline 2 & Saccharomyces cerevisiae NCIM 3391 & 3.26 & 3.53 & 4.01 & 3.60 & 20.44 & 18.83 & 17.74 & 19.00 \\
\hline 3 & Saccharomyces cerevisiae NCIM 3073 & 4.71 & 5.15 & 5.80 & 5.22 & 16.89 & 14.31 & 11.23 & 14.15 \\
\hline \multicolumn{2}{|r|}{ Mean } & 3.60 & 3.96 & 4.65 & 4.07 & 20.33 & 18.23 & 15.35 & 17.97 \\
\hline \multicolumn{2}{|r|}{ Source } & \multicolumn{2}{|c|}{$\mathrm{SEm} \pm$} & \multicolumn{2}{|c|}{$\mathrm{CD}$ at $1 \%$} & \multicolumn{2}{|c|}{ SEm \pm} & \multicolumn{2}{|c|}{$\mathrm{CD}$ at $1 \%$} \\
\hline & Strains (A) & \multicolumn{2}{|c|}{0.025} & \multicolumn{2}{|c|}{0.109} & \multicolumn{2}{|c|}{0.015} & \multicolumn{2}{|c|}{0.065} \\
\hline & Inoculum level (B) & \multicolumn{2}{|c|}{0.025} & \multicolumn{2}{|c|}{0.109} & \multicolumn{2}{|c|}{0.015} & \multicolumn{2}{|c|}{0.065} \\
\hline & Interaction (AXB) & \multicolumn{2}{|c|}{0.043} & \multicolumn{2}{|c|}{0.188} & \multicolumn{2}{|c|}{0.026} & \multicolumn{2}{|c|}{0.112} \\
\hline
\end{tabular}

Table.2 Effect of different yeast strains and inoculum levels on alcohol content and residual reducing sugars content in beer produced from buckwheat variety Niligiri local

\begin{tabular}{|c|c|c|c|c|c|c|c|c|c|}
\hline \multirow{3}{*}{ Sl. No. } & \multirow[t]{3}{*}{ Strains (A) } & \multicolumn{4}{|c|}{ Alcohol content $(\%)$} & \multicolumn{4}{|c|}{ Residual reducing sugar (mg/g) } \\
\hline & & \multicolumn{8}{|c|}{ Inoculum level(B) } \\
\hline & & $1.0 \%$ & $1.5 \%$ & $2.0 \%$ & Mean & $1.0 \%$ & $1.5 \%$ & $2.0 \%$ & Mean \\
\hline $\mathbf{1}$ & Saccharomyces cerevisiae NCIM 3430 & 1.57 & 2.27 & 4.11 & 2.65 & 28.73 & 25.54 & 18.79 & 24.35 \\
\hline 2 & Saccharomyces cerevisiae NCIM3391 & 2.72 & 3.73 & 4.75 & 3.73 & 22.44 & 20.83 & 17.77 & 20.35 \\
\hline 3 & Saccharomyces cerevisiae NCIM 3073 & 2.68 & 3.24 & 3.51 & 3.14 & 24.76 & 19.31 & 18.23 & 20.77 \\
\hline \multirow{2}{*}{\multicolumn{2}{|c|}{$\begin{array}{l}\text { Mean } \\
\text { Source }\end{array}$}} & 2.32 & 3.08 & 4.12 & 3.18 & 25.31 & 21.89 & 18.26 & 21.82 \\
\hline & & \multicolumn{2}{|c|}{ SEm \pm} & \multicolumn{2}{|c|}{$\mathrm{CD}$ at $1 \%$} & \multicolumn{2}{|c|}{ SEm \pm} & \multicolumn{2}{|c|}{$\mathrm{CD}$ at $1 \%$} \\
\hline \multicolumn{2}{|r|}{ Strains (A) } & \multicolumn{2}{|c|}{0.060} & \multicolumn{2}{|c|}{0.264} & \multicolumn{2}{|c|}{0.070} & \multicolumn{2}{|c|}{0.301} \\
\hline & Inoculum level (B) & \multicolumn{2}{|c|}{0.060} & \multicolumn{2}{|c|}{0.264} & \multicolumn{2}{|c|}{0.070} & \multicolumn{2}{|c|}{0.301} \\
\hline & Interaction (AXB) & \multicolumn{2}{|c|}{0.105} & \multicolumn{2}{|c|}{0.457} & \multicolumn{2}{|c|}{0.122} & \multicolumn{2}{|c|}{0.522} \\
\hline
\end{tabular}


Table.3 Effect of fermentation period on alcohol content and residual reducing sugars of buckwheat (PRB-1) beer

\begin{tabular}{|c|c|c|}
\hline No. of days & Alcohol (\%) & $\begin{array}{c}\text { Residual reducing sugars } \\
(\mathbf{m g} / \mathbf{g})\end{array}$ \\
\hline $\mathbf{5}$ & 5.84 & 11.22 \\
\hline $\mathbf{7}$ & 6.13 & 9.77 \\
\hline $\mathbf{1 0}$ & 6.47 & 9.16 \\
\hline Mean & 6.15 & 10.05 \\
\hline C.D. at 1 \% & 0.197 & 0.153 \\
\hline SEm \pm & 0.017 & 0.029 \\
\hline C.V. & 1.06 & 0.504 \\
\hline
\end{tabular}

Table.4 Effect of period of fermentation on $\mathrm{pH}$ and tannin content of buckwheat (PRB-1) beer

\begin{tabular}{|c|c|c|}
\hline $\begin{array}{c}\text { Period of fermentation } \\
\text { (days) }\end{array}$ & pH & Tannin content $(\mathbf{m g} / \mathbf{1 0 0} \mathbf{~ m l})$ \\
\hline $\mathbf{5}$ & 5.10 & 8.34 \\
\hline $\mathbf{7}$ & 4.60 & 7.53 \\
\hline $\mathbf{1 0}$ & 4.27 & 6.48 \\
\hline mean & 4.65 & 7.45 \\
\hline C.D. at 1 \% & 0.272 & 0.144 \\
\hline SEm \pm & 0.077 & 0.041 \\
\hline C.V. & 2.864 & 0.951 \\
\hline
\end{tabular}

pH

Results from Table 4 reveal that, $\mathrm{pH}$ is significantly influenced by the period of fermentation. Highest $\mathrm{pH}$ (5.1) was recorded on the fifth day of fermentation, which was significantly higher than seventh day of fermentation (4.6). Least $\mathrm{pH}$ (4.27) was recorded on the tenth day of fermentation. Different fermentation days showed a significant difference in terms of $\mathrm{pH}$ of beer. Similar experiment was performed by Nic Phiarais et al., (2010) on processing of top fermented beer from buckwheat malt and reported that the $\mathrm{pH}$ of the beer decreased from 5.7 to 4.4 from first day to fourth day of fermentation.

\section{Tannin content}

With increase in the fermentation period, there was a gradual decrease in the tannin content upto tenth day of fermentation. Highest tannin content $(8.34 \mathrm{mg} / 100 \mathrm{ml})$ was observed on the fifth day of fermentation, which was significantly higher than the tannin content observed on the seventh day of fermentation $(7.53 \mathrm{mg} / 100 \mathrm{ml})$. On the tenth day lowest tannin content $(6.48 \mathrm{mg} / 100 \mathrm{ml})$ was recorded in the beer (Table 4).

\section{References}

Caputi, A., Ueda, J. M. and Brown, T., 1968, Spectrophotometric determination of chromic complex formed during oxidation of alcohol. Am. J. Enol. Vitic., 19: 160-165.

Dezelak, M., Zarnkow, M., Becker, T. and Kosir, I. J., 2014, Processing of bottomfermented gluten-free beer-like 
beverages based on buckwheat and quinoa malt with chemical and sensory characterization. J. Inst. Brew., 120: 360-370.

Miller, G. L., 1959, Use of dinitrosalicylic acid reagent for determination of reducing sugars. Ann. Chem., 31: 426428.

Nic Phiarais, B. P., Mauch, A., Schehl, B. D., Zarnkow, M., Gastl, M. and Herrmann, M., 2010, Processing of a top fermented beer brewed from 100\% buckwheat malt with sensory. J. Inst. Brew.,
116(3): 265-274.

Panse, V.G. and Sukhatme, 1961, Statistical Methods for Agricultural Workers, ICAR, New Delhi, pp. 381.

Popovic, V., Sikora, V., Berenji, J., Filipovic, V., Dolijanovic, Z., Ikanovic, J. and Doncic, D., 2014, Analysis of buckwheat production in the world and Serbia. Econ. Agric., 61: 53-62.

Schanderl, S. H., 1970, Methods in Food Analysis. Academic Press, New York, 709.

\section{How to cite this article:}

Praja K. Malaganve and Geeta G. Shirnalli. 2020. Optimization of Fermentation Parameters for Beer Production from Buckwheat (Fagopyrum esculentum) Grains. Int.J.Curr.Microbiol.App.Sci. 9(06): 2721-2726. doi: https://doi.org/10.20546/ijcmas.2020.906.330 